\title{
COMO ANDA A PARTICIPAÇÃO? As CONDIÇÓES PARA A ELABORAÇÃo \\ DE PLANOS DIRETORES PARTICIPATIVOS
}

HOW IS THE PARTICIPATION GOING?

The CONDITIONS FOR ELABorating PARTicipative Master PLANS

\section{Elson Manoel Pereira}

Universidade Federal de Santa Catarina, Departamento de Geociências, Florianópolis, SC, Brasil

\begin{abstract}
R E S U M O : Este artigo analisa as condiçôes necessárias para uma participação de qualidade nos processos de elaboração de planos diretores municipais de ordenamento do solo. A partir de uma análise bibliográfica e de pesquisas realizadas pelo autor (PEREIRA, 2015), são apresentados os elementos considerados fundamentais para uma participação de qualidade: vontade política, tradição ou densidade participativa, existência de condiçōes institucionais e adesão dos técnicos de urbanismo ao processo participativo. Ao lado dessas condiçôes, enfatiza-se a necessidade de compreensão do território para a implantação da democracia participativa no desenvolvimento de políticas públicas urbanas. Por fim, há uma análise exemplificadora de como os elementos supracitados foram percebidos em um caso específico: o processo de elaboração do novo plano diretor de Florianópolis/SC.
\end{abstract}

P A L A V R A S - C H A V E : plano diretor; participação; planejamento urbano; território; Florianópolis.

A B S T R A C T : This article analyses the necessary conditions for quality participation in drafting municipal master plans for land use. From an analysis conducted on the literature and research (PEREIRA, 2015), we present the elements considered essential for quality participation: political will, participative tradition or density, the existence of institutional conditions and the adherence of urban technicians to the participatory process. In addition to these conditions, the article emphasizes the need for understanding the territory for the implementation of participatory democracy in the development of urban public policies. Finally, the article presents an exemplifying analysis of how these elements were perceived in one particular case: the process of developing the new Master Plan of Florianópolis/SC.

K E Y W O R D S : master Plan; participation; urban planning; Florianópolis; territory. 


\section{INTRODUÇÃO}

A história da participação em políticas públicas urbanas no Brasil remonta a experiências do fim dos anos 1970 e início da década de 1980: Lages, em Santa Catarina (1978-1982); Boa Esperança, no Espírito Santo (1978-1982); Diadema, em São Paulo (1982-1986) (TRANJAN, 2012). Não há dúvidas, porém, de que a experiência do Orçamento Participativo de Porto Alegre foi a de maior repercussão - não apenas no território brasileiro, mas também no contexto internacional. A experiência gaúcha, em sua essência, questionou até mesmo a visão hegemônica de democracia (isto é, liberal, representativa) do século XX (SANTOS, 2003). A demanda por participação, principalmente nos orçamentos participativos, apontou os limites da democracia representativa e a necessidade de ouvir os diversos atores sociais durante todo o mandato dos governantes, não se limitando ao período das eleiçôes. Pode-se afirmar, além disso, que a experiência dos Orçamentos Participativos influenciou igualmente a reflexão sobre tecnocracia, presente na definição dos destinos das cidades brasileiras por muito tempo (e ainda permanece assim em muitos casos).

A partir do capítulo sobre Política Urbana da Constituição Federal de 1988, começou a se desenhar uma nova institucionalização no Brasil. Seguiu-se, após a aprovação da constituição, uma série de eventos importantes, como a aprovação da Lei 10.257 (Estatuto da Cidade), a criação do Ministério das Cidades e do Conselho das Cidades, a realização das Conferências das Cidades etc. A necessidade de participação da população foi apresentada como um elemento central nessa nova institucionalização. O Movimento Nacional pela Reforma Urbana (MNRU), por meio de uma reflexão crítica sobre os problemas urbanos brasileiros, afirmava que o

[...] direito à Cidade àqueles historicamente excluídos das políticas urbanas das cidades brasileiras só aconteceria a partir de uma mudança radical na maneira de acesso à terra urbana e na maneira de planejar e gerir as cidades. A gestáo e o planejamento das cidades precisariam ser democratizados de forma a permitir que os grupos excluídos dos processos decisórios pudessem assumir a condiçáo de cidadãos plenos de direito (PEREIRA, 2015, p. 199).

Ato contínuo à criação de uma estrutura nacional de Política Urbana, foi lançada a Campanha Nacional para a elaboraçáo de Planos Diretores Participativos para os municípios, agora obrigatórios para alguns municípios brasileiros de acordo com o Estatuto da Cidade. Mais de 1.600 municípios elaboraram ou revisaram seus planos

1 A pesquisa "Os planos diretores municipais pós-estatuto da cidade: balanço crítico e perspectiva", encomendada pelo Ministério das Cidades e coordenada por Orlando Santos Júnior e Daniel Montandon, apresenta um balanco do conteúdo dos planos diretores participativos, relacionando-o com o conteúdo do Estatuto da Cidade. Ela é um marco importante na literatura sobre o assunto (SANTOS JÚNIOR, MONTANDON, 2011). diretores. Assim como ocorreu com os Orçamentos Participativos, os Planos Diretores Participativos foram e são alvo de inúmeros trabalhos acadêmicos que avaliam processos e resultados ${ }^{1}$. A exigência da participação mudou o caráter do planejamento urbano. Mas essa mudança de caráter foi observada também em outros contextos (CHALAS, 1998; NOVARINA, 2000). Neste artigo, nas diversas experiências ditas participativas, estamos interessados em estudar, particularmente, os elementos que, $a$ priori, contribuiriam para uma participação efetiva na definição de políticas públicas urbanas. A literatura sobre o tema aponta certas condiçôes para uma participação de qualidade (AVRITZER, 2003; LÜCHMANN, 2003): vontade política dos dirigentes em promover a participação, tradição ou densidade participativa da população envolvida no processo e condiçóes institucionais disponibilizadas para a participaçáo. 
Considerando o papel central e, por vezes, determinante dos técnicos de urbanismo nos processos de elaboração dos planos diretores, verificamos, em pesquisas recentes (PEREIRA, 2015), o quanto é importante dar atenção ao papel desses atores sociais no interior de tais processos ${ }^{2}$. Embora se observe uma certa relativização da ação do urbanista na definição das políticas públicas urbanas (CHALAS, 1998), a atuação desse profissional ainda se apresenta, no contexto brasileiro, como um fator importante para uma participação de qualidade.

Para além dessas condiçóes, há ainda um elemento de fundamental importância para a compreensão dos avanços e limites do planejamento urbano participativo: o papel exercido pelo(s) território(s), melhor dizendo, o papel dos atores sociais, econômicos e políticos nas disputas territoriais. Esse conceito geográfico - território - tem um papel crucial na compreensão dos conflitos que emanam de um processo participativo, muitos dos quais ficam ocultos ou dissimulados quando o planejamento apresenta um viés tecnocrático e a democracia não está presente. Tendo em vista esses aspectos, o objetivo deste artigo é analisar as condiçôes para uma participação de qualidade no âmbito do planejamento urbano e demonstrar como o conhecimento da condição territorial pode ajudar na compreensão dos limites e das possibilidades dos processos participativos em políticas urbanas. Como objeto empírico, utilizaremos a experiência do processo de elaboração do plano diretor participativo de Florianópolis/SC.

\section{A CRISE DA DEMOCRACIA PARTICIPATIVA E LIBERAL E A CRISE DO URBANISMO TECNOCRÁTICO}

Os anos sessenta do século passado foram de questionamento de várias práticas sociais no mundo ocidental. Foi um momento em que se pôs em xeque o próprio modelo hegemônico de democracia: a democracia representativa, aquela que se tornou "a forma padrão de organização política no interior da modernidade ocidental" (AVRITZER, 2003, p. 469). No entanto, segundo Boaventura de Sousa Santos, esse

[...] modelo hegemônico de democracia (democracia liberal, representativa) apesar de globalmente triunfante, não garante mais que uma democracia de baixa intensidade assente na privatizaçáo do bem público por elites mais ou menos restritas, na distância crescente entre representantes e representados e numa inclusão política abstrata feita de exclusão social (SANTOS, 2003, p. 27).

A discussão sobre o exercício dessa democracia de baixa intensidade nos remete à crise da democracia representativa e à emergência (ou à possibilidade) de outras formas de democracia, pois

[p]aralelamente a este modelo hegemônico de democracia, sempre existiram outros modelos, tais como a democracia participativa ou a democracia popular, apesar de marginalizados ou desacreditados. Em tempos recentes, um desses modelos, a democracia participativa, tem vindo a ganhar uma nova dinâmica, protagonizada por comunidades e grupos sociais subalternos em luta contra a exclusão social e a trivialização da cidadania,
2 Neste artigo, a experiência de Florianópolis é tomada como um exemplo para demonstrar como os quatro elementos mencionados concorrem para uma participação de qualidade. A hipótese de que eles são condições a priori para uma participação de qualidade em processos de elaboração de planos diretores fundamenta-se em pesquisas realizadas entre 2009 e 2014 sobre as experiências de elaboração de planos diretores participativos dos oito mais populosos municípios de Santa Catarina: Joinville, Florianópolis, Blumenau, Criciúma, São José, Chapecó Itajaí e Lages. 
mobilizados pela aspiraçáo de contratos sociais mais inclusivos e de democracia de mais alta intensidade. (SANTOS, 2003, p. 27).

No campo do conhecimento da cidade e de seu planejamento, dois textos marcaram profundamente a reflexão urbana da década de 1970: os livros Morte e Vida da Grande Cidade Americana, de Jane Jacobs, escrito em 1961 (JACOBS, 2011), que critica os princípios homogeneizantes e prescritivos do urbanismo modernista, e $O$ Direito à Cidade, de Henry Lefebvre, escrito originalmente em 1968 (LEFEBVRE, 2001), que, observando a solução francesa para o problema habitacional do pós-guerra, afirma que a cidade se limitou ao âmbito do habitat, náo oferecendo ao morador o direito ao "habitar". Enquanto a obra de Jacobs destaca questôes mais ligadas às formas urbanas, a de Lefebvre clama atenção para o direito da participaçáo e de apropriação da e na cidade.

A questão da participação em Lefebvre (2001) ultrapassa os limites da democracia participativa; ela reivindica o próprio fazer cotidiano da cidade. Para o autor francês, o Direito à Cidade deveria, entre outras coisas, garantir a possibilidade de os moradores urbanos apropriarem-se do espaço. Aqui, a apropriaçáo não se trata de uma referência à propriedade ou, ainda, à posse de terras ou imóveis na cidade. Tratase, antes, da vontade de ver o conjunto dos cidadáos capazes de fazer da cidade seu próprio lugar. O verbo latino appropriare deriva de ad proprius, que transmite a ideia de tornar próprio. Assim, o objetivo desse tipo de possessáo (a apropriação) é precisamente tornar próprio alguma coisa, ou seja, adaptar algo para si, e, desse modo, transformar essa coisa em um suporte da expressão de si (SERFATY-GARZON, 2003, p.27). Lefebvre (2001) externa, em seu livro, o desejo de que a nova cidade seja a imagem de seus moradores, um suporte da expressão do próprio habitar.

É claro o recurso ao marxismo quando Lefebvre (2001) evoca a teoria do valor: da mesma maneira que o trabalhador torna-se estranho ao valor de uso do produto fabricado pelo seu trabalho, o que contribui para sua alienação, o habitante da cidade aparece como alguém passivo, mergulhado numa cidade na qual está preso - ele não pode mais decidir seus usos. A necessidade de apropriação aparece, então, em Lefebvre, como uma vontade de dar poder à classe operária.

A reflexão urbana no Brasil, impulsionada, em especial, pela ação do MNRU, na busca de uma resolução para os problemas relacionados ao acesso à terra urbana, apontou para a necessidade de democratizar a elaboração e a gestấo de políticas públicas urbanas, a fim de diminuir tanto a tecnocracia presente no interior dos órgãos de planejamento estatais quanto a força das elites econômicas locais na definição das políticas e investimentos estatais na cidade.

A experiência do Orçamento Participativo de Porto Alegre lançou, no bojo da reflexão sobre a necessidade de democratizar as políticas públicas, uma séria discussão acerca da importância da democracia participativa para a construçấo da cidadania, superação das desigualdades urbanas e efetivação da cidade democrática. Segundo Avritzer (2003, p. 476), "a redemocratizaçâo brasileira envolveu, simultaneamente, grandes doses de continuidade política misturadas com algumas doses de inovação". Porto Alegre insere-se nesse contexto de inovação: em 1986, a Uniáo das Associaçóes dos Moradores de Porto Alegre afirmava seu intuito de "decidir sobre as prioridades de investimento de cada Vila, bairro e da cidade em geral” (AVRITZER, 2003, p. 478). Dois anos depois, um governo popular atendeu tal reivindicação, inaugurando 
uma das experiências de participação mais conhecidas na história contemporânea das cidades ocidentais.

O MNRU conseguiu, por ocasião da discussão da nova Constituição Federal, após o processo de redemocratização do país, inserir no texto da lei um capítulo sobre política urbana. Nele, o principal instrumento de planejamento urbano das cidades brasileiras - o Plano Diretor - teve sua importância destacada; posteriormente, foi regulamentado pela principal lei de política urbana existente no Brasil: o Estatuto da Cidade (BRASIL, 2001). Numa campanha sem precedentes, o Ministério das Cidades orientou, entre 2003 e 2006, a elaboração ou revisão de mais de 1.600 planos diretores, enfatizando a necessidade da presença do caráter democrático em cada um deles.

Assim, após um longo percurso, o qual misturou importação e transferências de ideias nascidas alhures, adaptaçóes e criações, o pensamento urbanístico crítico brasileiro parece ter assumido uma posição vanguardista no cenário mundial. Nele está presente a necessidade da participação dos atores sociais na elaboração das políticas públicas urbanas, bem como a clareza de que essa participação não acontece sem conflitos no contexto da história secular de um urbanismo tecnocrático fortemente enraizado no patrimonialismo e na tradição bacharelesca.

\section{UM URBANISMO MENOS HIERÁRQUICO E MAIS POLÍTICO}

Chalas (1998) fez uma relevante análise das mudanças ocorridas no âmbito do urbanismo no final do século XX. Esse autor, ao estudar a prática de urbanistas franceses em diferentes períodos (décadas de 1970 e 1990), constata o aparecimento de elementos caracterizadores de um novo planejamento urbano, que, mais que uma simples governança, "inscreve-se em uma tentativa de repolitização da vida urbana, apresentando-se como uma oferta de política, de conceitualizaçáo do conflito, para com os habitantes" (CHALAS, 1998, p. 206). Ele nos fala, então, de um novo imaginário de planejamento, denominado "pensamento fraco ou pensamento prático".

Segundo Chalas (1998, p. 206), pensamento fraco "é o contrário de um pensamento simples, de um pensamento repleto de certezas e orientado para perspectivas de futuro claramente traçadas. Um pensamento fraco é um pensamento tornado mais incerto, mais complexo, menos sistemático e, por isso mesmo, menos polêmico, menos constituído em doutrina”, um pensamento que apresentaria como dimensôes a prática da concertação ou da participação dos habitantes na escala local (la figure du quartier-prétexte) e a ausência de certezas, de modelos, de utopia, de visão de futuro hegemônicos.

O urbanismo prático ou do pensamento fraco enuncia-se, então, em cinco aspectos diferentes ou, antes, em cinco modalidades possíveis (CHALAS, 1998):

1. É um urbanismo náo espacialista ou náo globalizante - oposição clara à prática do urbanismo segundo o pensamento funcionalista, para o qual existiria uma ligação direta, mecânica e unívoca entre espaço construído e vida social;

2. É um urbanismo performativo ou não diretivo. Segundo Chalas (1998, p. 211), "o urbanismo pode ser qualificado de urbanismo prático quando sua ação consiste não mais em dar, na condição de especialista, soluçóes elaboradas aos seus 
próprios cuidados, nem mesmo em submeter suas soluçóes ao debate público, mas, sob sua ótica, em encontrar soluçôes ao menos a partir do debate público”;

3. É um urbanismo integrador ou sistêmico, e não sistemático, no qual se busca a adaptação recíproca das partes, compromisso entre objetivos de toda natureza e resultados ligados à inovação, invenção e criação;

4. É um urbanismo apofático ou urbanismo em negativo. Um urbanismo que se preocupa náo mais com a felicidade para todos, como preconiza o urbanismo funcionalista, mas com a mínima sujeição de ou com a mínima dificuldade para cada um na elaboração do projeto. "[E]le não parte do interesse geral que existiria a priori, que seria determinado ou conhecido em sua substância antes de qualquer ação, mas ele aí chega ao procurá-lo e ao produzi-lo coletivamente em função dos projetos" (CHALAS, 1998, p. 213);

5. Enfim, é um urbanismo político e menos tecnicista. A garantia de um urbanismo melhor ou de um urbanismo ótimo está no debate público e aberto, muito mais do que na excelência técnica, funcional e racional ou mesmo que em qualquer ideologia.

Dessa forma, a demanda pela participação em políticas públicas urbanas parece rivalizar com o próprio urbanismo, que, por muito tempo, procurou justificar-se a partir da retórica da cientificidade, da objetividade, da competência e da neutralidade, atuando, ao mesmo tempo, como instrumento repressivo e ideológico (SANTOS, 2015).

No entanto, como demonstra Chalas (1998), num momento de reivindicação por uma democracia de alta intensidade, o próprio urbanismo reinventa-se e abre-se à participação de outros atores sociais. Em algumas situaçóes, ele passa a ser menos ligado a modelos predefinidos, mais aberto ao debate e, portanto, mais político e participativo. O melhor projeto passa a ser não aquele que é necessariamente o melhor tecnicamente, mas sim o que é socialmente mais aceito (CHALAS, 1998).

Nesse contexto, as próprias instituiçóes passam a ser repensadas: as formas burocráticas, "monocráticas na forma como gerem o pessoal administrativo e na forma como advogam uma solução homogeneizante para cada problema enfrentado em cada jurisdição" (SANTOS, 2003, p. 42), não conseguem responder mais às necessidades das sociedades democráticas de alta intensidade.

\section{AS CONDIÇÕES PARA UMA PARTICIPAÇÃO DA POPULAÇÃO EM POLÍTICAS PÚBLICAS}

3 Apesar da farta e rica bibliografia sobre experiências participativas na elaboração de planos diretores municipais, optamos por partir da análise da literatura sobre democracia e institucionalidade, na medida em que "o contexto institucional também exerce influência, no sentido de oferecer estruturas de oportunidades diferenciadas para a participação" (LÜCHMANN; BORBA, 2008, p. 61).
Ora, dada a passagem (ou a procura de uma passagem) de uma democracia de baixa intensidade para uma democracia de alta intensidade, é necessário perguntar em quais condições pode ser exercida essa prática mais democrática de política urbana? Como o objetivo do texto está ligado à análise das condiçôes para o exercício da participação, privilegiamos os indicadores de participação a priori (condiçóes dadas), e, por isso, partimos do estudo de Lüchmann $(2003)^{3}$, que apresenta três elementos fundamentais para que a participação da população seja considerada de qualidade no desenvolvimento de uma política pública:

(1) A Tradição Associativa: a organização da sociedade civil é um fator relevante para a implementação de mecanismos participativos, uma vez que "[...] a preexistência de práticas participativas ao nível da sociedade civil aumenta as chances de sucesso 
dos arranjos participativos introduzidos pelas administraçóes públicas em nível local" (AVRITZER, apud LÜCHMANN, 2003, p. 167).

Na América Latina, especificamente no Brasil, o conceito de sociedade civil é, para Lüchmann (2003, p. 167), aquele que "melhor tem expressado o surgimento e a potencialidade democrática desse associativismo, ou de identidades coletivas". De acordo com a autora, "a concepçáo de Sociedade Civil se fundamenta no conjunto de práticas associativas ou coletivas autônomas do Estado" (LÜCHMANN, 2003, p. 167), embora, com o fim da ditadura militar, uma concepção homogeneizadora tanto da sociedade civil quanto do Estado - tenha sido relativizada:

[...] por um lado, sob a vigência das regras democráticas do Estado de Direito [...], as diferenças e clivagens no campo da sociedade civil $v$ [iera $] \mathrm{m}$ à tona, desnudando uma esfera extremamente complexa e heterogênea. Por outro lado, novas articulaçóes entre Estado e Sociedade [...], mediadas por novos mecanismos de gestão pública de caráter participativo [tornaram-se] indicadores da complexidade e heterogeneidade do campo próprio da organização estatal (LÜCHMANN, 2003, p.168).

Lüchmann (2003) ainda acrescenta que, num contexto de consolidação democrática, pós-ditadura militar, uma fase menos combativa e mais propositiva passa a estabelecer novas relaçôes, e o caráter público da sociedade civil se amplia. A participação alcança inclusive uma natureza jurídica que lhe imprime um caráter legal.

(2) Vontade Política: segundo Velasquez (apud LÜCHMANN, 2003), para uma participação de qualidade, é central o grau de abertura, isto é, a vontade de comprometimento do sistema político às demandas de participação, como elo condutor da implementação de espaços públicos deliberativos e de investimentos na mudança das prioridades sociais.

Essa centralidade da vontade política fundamenta-se em três razóes: primeiramente, na existência da necessidade de dar universalidade à aglutinação e representação de muitos e variados interesses inerentes a uma sociedade marcada por ampla desigualdade, e só as instâncias propriamente políticas, o poder do Estado e as organizaçóes partidárias poderiam fazer isto; em segundo lugar, na importância do Poder Público para estimular e desenvolver mecanismos que permitam ou potencializem a ampliação de um associativismo civil atuante e vigoroso; por último, na necessidade de uma instância responsável pela promoção de ações que tenham em vista a inclusão, a criação de mecanismos de salvaguarda do princípio de igualdade participativa e a promoção de medidas pautadas na efetivação da justiça social. É nessa perspectiva que se destaca a combinaçáo entre vontade e empenho do governo com tradição associativa sólida - elementos centrais na avaliação do maior ou menor sucesso das experiências participativas. Poderíamos resumir esse ponto como a necessidade de projeto, vontade e comprometimento político do governo, no caso deste artigo, do governo municipal.

(3) Desenho institucional: para que as

[...] experiências participativas adquiram um caráter de inovação institucional em direção à efetivação da democracia deliberativa, faz-se necessário não apenas que se introduza um conjunto mais amplo e representativo dos diferentes segmentos e atores sociais [...] como também que se introduza um conjunto de práticas, regras e critérios (procedimentos) que 
interfiram positivamente nas condiçôes subjacentes de desigualdades socais [...], ampliando tanto as possibilidades de participação aos setores historicamente excluídos quanto ampliando a densidade e a qualidade da representação (LÜCHMANN, 2003, p. 169).

É válido ressaltar, seguindo Lüchmann (2003), a importância do desenho institucional. As experiências participativas necessitam de elementos, mecanismos, regras institucionalizadas (estabelecidas de modo igualmente participativo) para ampliar suas possibilidades.

Ao lado das três condiçôes apresentadas por Lüchmann (2003), nossas pesquisas e a própria literatura sobre o tema do artigo forneceram-nos elementos que nos permitem afirmar que, no caso específico do planejamento urbano, uma quarta condição parece também concorrer para uma participação de qualidade em políticas locais de desenvolvimento urbano: o comprometimento dos técnicos envolvidos no processo de planejamento com o princípio participativo. Parece haver uma mudança de princípios no planejamento urbano - de um modelo hierárquico, com referencial forte, para um modelo negociado, processual e político (CHALAS, 1998; NOVARINA, 2000). Ao indicar essa mudança, no entanto, não queremos afirmar que ela tenha acontecido de forma linear, sem contradiçóes. No caso do planejamento urbano, há uma tradiçâo forte do funcionalismo e da tecnocracia; essa tradição perdurou por todo o século XX no contexto brasileiro, tanto nas escolas que formaram os técnicos de urbanismo, como nas agências públicas de planejamento. A adesão ao modelo democrático não se dá, assim, de forma automática. Existem resistências, adesóes parciais, dúvidas, medo de perda de poder, desconfiança, críticas aos tempos diferentes dos diversos atores, assim como comprometimento com o processo participativo por parte de alguns técnicos de urbanismo. Essas diferenças de postura frente ao processo participativo levam também a diferenças nos processos participativos.

\section{O PAPEL DO TERRITÓRIO}

Ao lado das condiçôes descritas, não podemos negligenciar as especificidades espaciais dos lugares onde as experiências participativas ocorrem. A compreensão da necessidade de articulação entre participação e espaço urbano e participação e território nos leva a pensar com mais profundidade sobre a contribuiçẫo específica do conhecimento geográfico ao planejamento urbano, pois o espaço urbano e o poder exercido sobre ele refletem o conjunto da vida social. O espaço urbano concentra as relaçôes e a dinâmica da sociedade contemporânea. A cidade é o meio, é o palco. Mas a cidade, seu espaço, também é um meio que condiciona os processos espaciais. Portanto, o espaço urbano é um meio e uma condição para os processos espaciais, para as relaçôes que são estabelecidas e/ou materializadas.

Dessa forma, os processos sociais, como o planejamento urbano e seus produtos, são gerados a partir da forma, da estrutura e das funçóes que a cidade previamente apresenta. A cidade, sua forma e sua dinâmica são condiçôes para a expressão espacial das relaçóes na sociedade. O planejamento urbano nasce, nesse sentido, a partir daquilo que já existe e já exerce influência.

$\mathrm{O}$ desconhecimento de muitos urbanistas dessa articulação dialética entre 
espaço urbano, estrutura social, relaçôes de poder e planejamento conduziu à elaboração de muitos planos completamente desconectados da realidade. No lugar de compreender a cidade para depois planejá-la, muitos imaginavam um futuro, a partir do qual analisavam (julgavam) o presente do espaço planejado (visão teleológica): aquilo que não estava de acordo com o futuro imaginado deveria ser modificado. No entanto, as experiências mostraram que o planejamento contemporâneo não pode prescindir da compreensão geográfica do espaço e do território; essa abordagem nos permite não apenas planejar, mas também compreender os processos participativos de planejamento analisados, pois a dificuldade de compreensão dos conflitos nos processos de planejamento urbano, tanto nos processos ditos tradicionais como nos de planejamento participativo, tem sua explicação nas análises insuficientes e na importância dada à cidade que já existe e seu potencial de influir no futuro.

Não é apenas a territorialização das políticas públicas que nos interessa; interessanos também o papel das disputas territoriais no processo de implantação de Políticas Públicas, especificamente das Políticas Públicas ligadas ao Planejamento Urbano.

Uma de nossas hipóteses de pesquisa é a de que o planejamento urbano participativo, quando atinge certo grau de participação, vai refletir a forma como as relaçôes sociais de poder são exercidas sobre o território por diferentes atores sociais.

\section{UM EXERCÍCIO DE ANÁLISE: O PLANO DIRETOR DE FLORIANÓPOLIS}

Florianópolis, capital de Santa Catarina, é a menor capital da região Sul do Brasil, não sendo nem mesmo a cidade mais populosa do Estado. Sua condição de capital e de sede de várias empresas públicas lhe permitiu por muito tempo receber investimentos públicos; no entanto, sua função portuária do século XIX e início do XX foi assumida por outros portos do interior catarinense (Itajaí, São Francisco do Sul, Imbituba e Navegantes). A economia diversificada do Estado, com vários polos econômicos distribuídos pelo interior (Joinville, Blumenau, Chapecó, Criciúma, Itajaí), não concedeu à capital o caráter polarizador em relação ao restante do território catarinense. Nos últimos quarenta anos, o turismo passou a ter uma grande importância em sua economia, bem como a construção civil.

As condiçôes físicas de seu território marcam fortemente sua ocupação: a maior parte do município ocupa a ilha de Santa Catarina, que, por sua vez, é constituída por áreas legalmente protegidas, como manguezais, dunas, morros e lagoas. Desde os anos 1980, Florianópolis tem recebido uma migração de outras cidades do Estado e do resto do país, em função de seus bons índices de qualidade de vida e das amenidades próprias de seu sítio natural.

Em termos de planejamento territorial, o município elaborou seu primeiro plano diretor em 1955, com baixa repercussão urbana. Seu segundo plano, aprovado em 1976, no entanto, marcou fortemente o território. Ambos tinham por princípio promover o crescimento da cidade, considerado como algo necessário para consolidar sua condição de capital do Estado. Um terceiro plano foi aprovado em 1997, o qual, de certa forma, ratificou os princípios do plano de 1976, embora tenha apresentado as primeiras preocupaçóes com os aspectos negativos do crescimento urbano. A partir de 1980, começaram a surgir na cidade os primeiros 
movimentos sociais que questionavam o modelo de crescimento da cidade, baseado na construção civil e no turismo.

Em julho de 2006, a Prefeitura Municipal de Florianópolis, por meio do Instituto de Planejamento Urbano (IPUF), iniciou um processo de revisão do plano diretor de 1997. Essa revisão, por força da Lei 10.257/2001, deveria ter a participação da população e, nesse sentido, inaugurava uma prática ausente nos planos de 1955 e 1976 e incipiente no de 1997. A metodologia de elaboração do plano, iniciada em 2006, tinha em sua gênese um desenho institucional bastante conservador: haveria um Núcleo Gestor (como previsto nas metodologias propostas pelo Ministério das Cidades) composto de 26 representantes do Poder Público e da sociedade civil; esse organismo representativo iria propor um documento (num prazo de três meses) constituído de Diretrizes para o Planejamento da Cidade. Para o Poder Público, esse documento seria, em si, uma peça do plano diretor, livrando o prefeito de qualquer sanção por não ter cumprido os prazos ditados pela Lei 10.257/2001. Nesse desenho institucional, o controle do processo era relativamente fácil de ser feito pela estrutura político-administrativa, pois, mesmo que os representantes da prefeitura fossem minoria no contexto do Núcleo Gestor - 11 entre o total de 26 representantes -, a sociedade civil nele representada era politicamente heterogênea e um número suficiente de seus representantes (Sindicato das Indústrias da Construção Civil, Associação Comercial Industrial de Florianópolis, Clube dos Dirigentes etc.) compartilhava da mesma visão de cidade da administração municipal. Contudo, durante a audiência pública para o lançamento do plano, representantes da população propuseram a introduçáo de 13 novos membros no Núcleo Gestor; elevando o número de representantes para 39, os quais representariam cada um dos 12 distritos do território municipal (a um dos distritos - o Distrito Sede - foram dadas duas representaçóes devido à sua dimensão), alterando, assim, o desenho institucional proposto pela prefeitura. Além da alteração da composição do Núcleo Gestor, os presentes na audiência pública propuseram a promoção de debates locais em cada distrito e, ainda, a construção de uma estrutura distrital para discussão do plano, o que criou uma maior permeabilidade para a participação da população. A partir desse novo desenho institucional, o processo, de certa forma, fugiu ao controle do Poder público. Após dois anos de participação intensa, o conjunto de distritos apresentou mais de três mil propostas que, de maneira geral, deixavam transparecer um modelo de cidade diferente daquele historicamente desenvolvido em Florianópolis. Era, nas palavras de Santos Júnior (2007, p. 301), a "cidade-direito" contrapondo-se à "cidademercado":

A questão é reconhecer que nesse processo, que combinou lutas sociais e reflexões conceituais, desenvolveu-se um novo paradigma, ou, mais exatamente, desenvolveram-se as bases de um novo paradigma, identificado ao campo da reforma urbana, que podemos denominar da cidade-direito, caracterizado pela construção de diagnósticos críticos da questão urbana brasileira e pela proposição de estratégias para um projeto alternativo de cidades.

O paradigma da "cidade-direito" estaria, segundo o autor, em construção, "tanto em relação ao aspecto teórico quanto em relação ao da práxis sociopolítica" (SANTOS JÚNIOR, 2007, p. 307). Ele "afirma o papel central do poder público no 
planejamento urbano e o seu compromisso com o enfrentamento dos mecanismos de produção de desigualdades e exclusão decorrentes da vigência da dinâmica do mercado no uso e ocupaçáo do solo urbano e do controle do poder político pelos históricos interesses patrimonialistas" (SANTOS JÚNIOR, 2007, p. 307). Na visão de cidade que tem o mercado como centro dos interesses, a participação política seria dada a partir do "reconhecimento dos agentes como clientes-consumidores, portadores de interesses privados, impedindo a construção de uma esfera pública que represente o interesse coletivo" (SANTOS JÚNIOR, 2007, p. 306). Diluemse as ideias de totalidade e de cidadania, que perde sua conexão com a ideia de universalidade; divide o espaço político entre "hipercidadãos e subcidadãos".

Essas duas visóes conflitantes de cidade apresentam, a nosso ver, seus pares metodológicos de elaboração de planos de urbanismo: a visão da cidade-direito indica a participação como uma forma privilegiada no processo de planejamento, pois "o direito à cidade se manifesta como forma superior dos direitos: direito à liberdade, a individualização na socialização, ao habitat e ao habitar. O direito à obra (à atividade participante) e o direito à apropriação (bem distinto do direito de propriedade) se implicam no direito à cidade" (LEFEBVRE, 2001, p. 155). Por sua vez, a visão da cidade-mercado continua afirmando o valor inconteste da expertise na conduçáo de planos urbanos; o discurso técnico e apolítico continua sendo usado ideologicamente como instrumento de busca de consensos diante da população.

As oficinas distritais no processo participativo da capital catarinense permitiram uma rica experiência de leitura comunitária, por terem sido a representação de "canais de participaçáo que resulta[r]am de intensa mobilização e ti[veram] como objetivo central concentrar as falas da população geral do distrito" (NOZAKI, 2009, p. 65). O entendimento da população em relação à leitura comunitária direcionou a qualidade dos assuntos debatidos nesses espaços, o que influenciou a qualidade da participação comunitária (NOZAKI, 2009).

Podemos afirmar também que houve, no período que ia de 2006 a 2008, certa adesão dos técnicos do IPUF ao processo participativo, visto que as condiçóes institucionais e a vontade política, principalmente do presidente do órgão de planejamento à época, influenciaram positivamente na forma como os técnicos lidaram e adaptaram-se à nova metodologia participativa de planejamento urbano. De certo modo, a mudança do desenho institucional no início do processo participativo subverteu o próprio processo.

No entanto, a composição política do governo municipal era claramente conservadora e ligada às forças econômicas tradicionais locais, sejam aquelas que se relacionavam ao capital imobiliário, sejam as que se atrelavam ao setor turístico hoteleiro. A esses setores da economia, não interessava a limitação da ocupação do território municipal apontada nas propostas discutidas nas reuniōes distritais.

No início de 2009, diante desse quadro adverso às suas vontades e sem conexão com o que fora previsto inicialmente pelo prefeito municipal, o processo de elaboração do plano em Florianópolis mudou de rumo. A prefeitura dissolveu o Núcleo Gestor e os Núcleos Distritais, desmontando toda a infraestrutura de apoio às bases distritais. A justificativa foi a de que o plano iniciaria uma "fase técnica", dirigida por uma empresa de consultoria, a Consultoría de Estudios y Proyectos del Ambiente S/A (Fundação CEPA).

A dissolução do núcleo gestor e dos núcleos distritais desmobilizou, em parte, a participação direta dos atores sociais. O plano passou a ser elaborado de maneira 
fechada pela empresa de consultoria contratada. Em novembro de 2009, a prefeitura realizou uma audiência pública para divulgar as diretrizes do plano, a "leitura da cidade", elaborado pela consultoria. As diretrizes deveriam expressar o conjunto das diretrizes originadas da "leitura comunitária" e as da "leitura técnica", construídas nos primeiros anos de elaboração do plano. Depois da divulgaçáo das diretrizes do plano, foram realizadas oficinas para apresentar e discutir a proposta elaborada pela Fundação CEPA.

Em 2010, a prefeitura pretendia apresentar o plano diretor elaborado pela CEPA, reintitulado de "Plano Diretor de Desenvolvimento Sustentável de Florianópolis", em lugar de "Plano Diretor Participativo de Florianópolis". A audiência pública para apresentaçáo do plano, marcada para 18 de março de 2010, não pôde ocorrer, pois uma manifestação popular de protesto contra a interrupção da participação da população na elaboração do plano impediu a realizaçáo da reunião promovida pela prefeitura. Sem a audiência pública, o plano não pôde ser enviado à câmara municipal. Esse impasse perdurou por quase dois anos, e não foi superado até as eleiçóes municipais que aconteceram no final de 2012 e que substituíram o prefeito que dera início ao processo de elaboração do plano.

Segundo Sampaio (2016, p. 52):

Por quase um ano, de abril de 2010 ao final de março de 2011, pouco se viu e ouviu falar sobre o PDP. Isto porque as atividades referentes ao Plano com a participaçáo da sociedade civil se mantiveram interrompidas após o conflito que se estabeleceu em torno dele. Contudo, durante este período de pouca movimentação, algumas comunidades e representaçóes do NG se empenharam tentando garantir a reabertura do acesso à participaçáo no processo do PDP. Alguns documentos elaborados por representaçóes do chamado "NG Autoconvocado" (composto por alguns representantes do NG destituído, inclusive de alguns NDs) foram enviados à procuradora da República, Ana Lúcia Hartmann, requerendo, principalmente, a restituição do NG e a "garantia de uma metodologia efetivamente participativa" no processo do PDP.

É um período que pode ser classificado como sendo de baixa vontade política para promover a participação, com ausência de condiçôes institucionais participativas e dissociação entre a ação dos técnicos e a participação comunitária.

Em 2013, já sob nova administração, a prefeitura buscou a continuidade do processo de elaboraçáo do Plano Diretor Municipal. A nova composição política do executivo municipal, apesar de ter sido eleito a partir de um discurso crítico ao ritmo da construção civil na cidade e a favor da participação da população no processo de construçáo do plano diretor, mantinha claros compromissos com os grupos econômicos tradicionais da cidade; mais do que o compromisso com o processo participativo, parece ter prevalecido o compromisso de campanha eleitoral de celeridade e de aprovação do plano ainda no primeiro ano de mandato do prefeito eleito. Essa celeridade estava ligada, provavelmente, à necessidade de o empresariado da construção civil ter garantias legais para suas açôes no território municipal. Também é importante considerar que o novo coordenador do plano, o presidente do IPUF nomeado pelo prefeito, não tinha acompanhado o processo participativo até então, embora fosse um arquiteto reconhecido na cidade por suas ideias comprometidas com a urbanidade e com a valorização de espaços públicos. Houve um movimento 
inicial de aproximação entre a prefeitura - por meio dos novos técnicos dirigentes do planejamento urbano da cidade - e os atores sociais que estavam no processo participativo desde 2006; o próprio Núcleo Gestor Municipal foi recomposto. Entretanto, havia um impasse entre muitos dos integrantes do Núcleo Gestor, os quais exigiam que as reuniôes distritais fossem retomadas para que fossem validadas as diretrizes acordadas no final de 2008, num claro compromisso com a participaçáo, e os novos dirigentes do IPUF, que queriam dar celeridade ao processo. Em setembro de 2013, tendo seus interesses contrariados, os dirigentes municipais destituíram novamente o Núcleo Gestor e o presidente do IPUF tomou para si a responsabilidade de dar uma forma final ao projeto de lei do novo plano diretor:

No dia 06 de setembro de 2013, aconteceu uma reuniáo do NG, na qual ocorreu uma votaçáo sobre o calendário final das atividades do PDP para os meses seguintes, com duas propostas distintas. De um lado, a Prefeitura e o IPUF defendiam a realizaçáo de Audiências Públicas Regionais, de outro lado, outros representantes do NG e NDs defendiam a realização de no mínimo 13 Audiências Públicas (APs) Distritais - além das APs Municipais. Com 16 votos a favor, 5 contra e uma abstenção, venceu a proposta das APs Distritais. Segundo um relato de um representante distrital presente na reunião, o superintendente do IPUF, Dalmo Vieira, disse que "não acataria o resultado da votação", encerrando a reuniáo antes do horário previsto (SAMPAIO, 2016, p. 54).

Dessa forma, o órgão de planejamento municipal preparou um plano à revelia das comunidades. A entrega do novo projeto de lei aconteceu em outubro. O novo plano era desconhecido da populaçáo; nem mesmo aos vereadores da Câmara Municipal foi dado o tempo necessário para o conhecimento do plano, que foi aprovado de maneira célere em todas as comissóes do parlamento municipal e aprovado em plenário em apenas 30 dias. Ao projeto de lei, foram apresentadas centenas de emendas: mais de 300 delas pelo próprio poder executivo, proponente da peça legislativa. As emendas chegaram à Câmara de Vereadores pouco antes da votaçáo em segundo turno e foram votadas em bloco, sem conhecimento de seus conteúdos por parte dos vereadores: as emendas que tiveram parecer favorável do órgáo de planejamento foram aprovadas pela base do governo na câmara, já aquelas que tiveram parecer desfavorável foram rejeitadas.

Segundo um dos vereadores que votaram contra, o projeto de lei foi enviado com atraso a todos os vereadores, apenas três dias antes da votação. Com isso, ele afirmou desconhecer o conteúdo do projeto por completo, pois não teve tempo suficiente para ler e analisá-lo e que por isso não poderia votar a favor de sua aprovaçáo, justificando seu voto contra. Quando questionado, no momento da votaçáo, o vereador presidente da Câmara, que votou a favor, também reconheceu seu desconhecimento sobre o conteúdo completo do projeto por falta de tempo para lê-lo por completo, mas disse que ele e os demais estavam "votando em confiança", ou seja, que votavam a favor por confiarem na adequaçáo de todas as emendas propostas pelos integrantes da Câmara (SAMPAIO, 2016, p. 58).

O prefeito cumpria, assim, sua promessa de campanha de votar o plano diretor em seu primeiro ano de mandato. Apesar disso, não demonstrou nenhuma vontade política de promover a participação. Praticamente não foram dadas as condiçóes institucionais para a participação no final do processo de elaboração do plano: ao 
4 Em dissertação de mestrado recentemente defendida no Programa de Pós-Graduação em Geografia da UFSC, Juliana Búrigo Sampaio (2016) fez um estudo específico sobre a relação entre as condições territoriais e o Plano Diretor Participativo de Florianópolis. contrário, a populaçáo foi afastada da Câmara Municipal a partir do uso da força da Guarda Municipal. Os técnicos que estavam à frente do "novo" plano justificavam-se com o discurso da competência. À população, coube esperar até janeiro de 2014 para conhecer o plano, quando então ele foi publicado em diário oficial.

Aprovado e publicado, foi permitida a análise do conteúdo do plano. Tal análise permite-nos corroborar uma hipótese sobre a relação entre território e processos participativos. Não obstante todos os problemas observados no processo de Florianópolis, percebemos que algumas comunidades conseguiram fazer valer suas demandas graças à tradição participativa (ou densidade participativa) apresentada, que se manifestou pelo exercício de uma forte territorialidade. Foi o caso da Comunidade do Campeche, que possui uma demanda histórica pela prevalência da baixa densidade e do gabarito de dois pavimentos em todo o seu distrito. Num município onde a indústria da construção civil apresenta uma força muito grande na definição dos índices urbanísticos, sempre na busca de maiores densidades e gabaritos, esse aspecto é muito relevante ${ }^{4}$. A garantia dessas demandas também foi observada em outras comunidades que tiveram importante participação no processo, como o Distrito de Santo Antônio de Lisboa ou o bairro de Coqueiros, que defenderam, igualmente, a limitação de índices construtivos em seus territórios. Por outro lado, em outros territórios da cidade em que não se pôde observar tal participação, o Poder Público aumentou de maneira considerável as possibilidades construtivas, por exemplo, a parte continental do município em torno da via de acesso à cidade (via expressa continental). Vale lembrar que o bairro do Campeche foi historicamente visado como área de expansão do capital imobiliário da cidade (desde o plano de 1976), sendo a limitação de sua ocupação resultado de anos de mobilização da população local. Ele talvez se constitua como o principal locus de conflito territorial da cidade.

Em março de 2014, a Justiça Federal em Florianópolis suspendeu o plano alegando que sua tramitação não seguiu a legislação federal, particularmente em relação à participação. Após ter sido derrubada preliminarmente no Tribunal Regional Federal da 4a Região em abril de 2014, a suspensão do plano foi ratificada em junho de 2015 pelo mesmo órgão federal, que exigiu, então, a realização de novas audiências públicas. Mais uma vez, o Núcleo Gestor foi convocado; novas oficinas, audiências distritais e municipais foram organizadas pela prefeitura. Passaram-se dez anos entre o início do processo e o momento atual - tempo que se apresentou repleto de conflitos, avanços e retrocessos participativos, demonstrando que a luta pela participação está no caminho correto, pois só ela pode evidenciar os conflitos territoriais, os quais, num processo não participativo, não seriam evidenciados.

\section{CONSIDERAÇÕES FINAIS}

A análise dos processos participativos na elaboração de planos diretores de ordenamento territorial a partir das quatro condiçôes apresentadas como necessárias para uma participação de qualidade permite conclusôes importantes, bem como o aprofundamento da teoria participativa.

Por um lado, parece-nos pertinente dizer que, de um modo geral, a análise das quatro condiçôes para uma participação de qualidade em conjunto com as condições territoriais permite uma melhor compreensão dos processos de elaboração 
de planos diretores participativos. Por outro, das situaçôes particulares, é possível perceber alguns aspectos que nos ajudam a entender o processo geral. Esse é o caso do processo participativo de elaboração do plano de Florianópolis, que aponta diferentes elementos de análise, por exemplo, a força da sociedade civil em subverter o desenho institucional proposto pelo Poder Público no início do processo, com vistas a melhorar as condiçóes de participação. Nesse processo, a celeridade pareceu justificar o desenho oficial proposto; por sua vez, uma participação de qualidade esteve na base dos argumentos da população ao propor um novo desenho institucional. Isto indica as diferentes temporalidades envolvidas e em consonância com as visōes dos diferentes atores: no caso do Poder Público, o prazo final para elaboração/revisão dos planos diretores de acordo com o Estatuto da cidade ditou o desenho institucional. Para a população, o importante era a participação efetiva, mesmo que isso demandasse mais tempo.

O processo participativo mostra que a vontade política para promover a participação tem um papel, senão determinante, importante na conduçáo do processo. A participação tem também o mérito de evidenciar conflitos não manifestos em processos tecnocráticos; ela fortalece territorialidades construídas a partir de uma cultura ou da densidade participativa de certas comunidades, aumentando as horizontalidades, nos termos de Santos (2005, p. 256). O outro lado da moeda reside no fato de que, quando as comunidades náo exercem uma territorialidade mínima, a territorialidade do capital, em especial do capital imobiliário, é claramente estabelecida e o espaço urbano, por sua parte, passa a ser visto não como espaço de vida, mas como locus de investimento do capital excedente.

\section{REFERÊNCIAS}

AVRITZER, L. Modelos de deliberação democrática: uma análise do orçamento participativo no Brasil. In: SANTOS, B. S. (Org.). Democratizar a Democracia: os Caminhos da democracia participativa. Porto: Afrontamento, 2003. p. 561-597.

BRASIL. Lei 10.257 (Estatuto da Cidade), 10 jul. 2001.

CHALAS, Y. O Urbanismo: pensamento "fraco" e pensamento prático. In: PEREIRA, E. (org). Planejamento Urbano no Brasil: conceitos, diálogos e práticas. Chapecó: Argos. 2008. p. 19-42.

JACOBS, J. Morte e vida das grandes cidades. Sáo Paulo: Martins Fontes, 2011.

LEFEBVRE, H. O Direito à Cidade. São Paulo: Centauro, 2001.

LÜCHMANN, L. Redesenhando as relaçôes da sociedade e do Estado: o tripé da democracia deliberativa. Katálysis, v. 6, n. 2, p. 165-178, jul./dez. 2003. Disponível em: <https:// periodicos.ufsc.br/index.php/katalysis/article/view/6450>. Acesso em: 20 fev. 2016.

.; BORBA, J. Participação, desigualdades e novas institucionalidades: uma análise a partir de instituições participativas em Santa Catarina. Ciências Sociais Unisinos, v. 44, n. 1, p. 58-68, jan./abr. 2008. Disponível em: <http://revistas.unisinos.br/index.php/ ciencias_sociais/article/view/5266>. Acesso em: 20 fev. 2016.

NOVARINA, G. Conduite et négociation du projet d'urbanism. In: SÖDERSTROM, O. et al. (Org.). L’usage du projet. Lausanne: Editions Payol, 2000. p.51-64.

NOZAKI, T. A prosa dos espaços públicos distritais no Plano Diretor Participativo de Florianópolis/SC. 2009. Trabalho de Conclusão de Curso (Graduação em Geografia) - Centro de Filosofia e Ciências Humanas, Universidade Federal de Santa Catarina, Florianó-

\begin{abstract}
Elson Manoel Pereira é graduado em Engenharia Civil e mestre em Administração pela Universidade Federal de Santa Catarina (UFSC); doutor em Urbanisme et Aménagement pelo Institut d'Urbanisme de Grenoble, França; professor no Departamento de Geociências da UFSC. E-mail: elsonmp@hotmail. com

Artigo recebido em 16 de maio de 2016 e aprovado para publicação em 21 de setembro de 2016.
\end{abstract}


polis, 2009.

PEREIRA, E. M. (Org.). A Alegoria da Participação: Planos Diretores Participativos pós-Estatuto da Cidade. Florianópolis: Insular, 2015.

SAMPAIO. J. Disputas territoriais e processo participativo em Florianópolis. 2016. Dissertação (Mestrado em Geografia) - Centro de Filosofia e Ciências Humanas, Universidade Federal de Santa Catarina, Florianópolis, 2016.

SANTOS, B. S. (Org.). Democratizar a Democracia: os Caminhos da democracia participativa. Porto: Afrontamento, 2003.

SANTOS, M. O retorno do território. In: OSAL : Observatório Social de América Latina. Ano 6 no. 16 (jun. 2005). Buenos Aires : CLACSO, 2005.

SANTOS, S. S. Entre transformaçôes e permanências: os institutos de planejamento urbano de Florianópolis e Joinville. 2015. 628 f. Tese (Doutorado em Geografia) Centro de Filosofia e Ciências Humanas, Universidade Federal de Santa Catarina, Florianópolis, 2015. Disponível em: <https://repositorio.ufsc.br/xmlui/bitstream/ handle/123456789/158886/336977.pdf>. Acesso em: 20 fev. 2016.

SANTOS JÚNIOR, O. Cidade, cidadania e planejamento urbano: desafios na perspectiva da reforma urbana. In: FELDMAN, S; FERNANDES, A. (Org.). O urbano e o regional no Brasil contemporâneo: mutações, tensōes, desafios. Salvador: EDUFBA, 2007. p. 293-314.

_; O. MONTANDON, D. (Orgs). Os planos diretores municipais pós-estatuto da cidade: balanço crítico e perspectivas. Rio de Janeiro: Letra Capital/Observatório das Cidades, 2011.

SERFATY-GARZON. L'appropriation. In: SEGAUD, M.; BRUN, J.; DRIANT, J. (Org.). Dictionnaire critique de l'habitat et du logement. Paris: Armand Colin, 2003. p. 27-30.

TRANJAN, R. Les racines de la démocratie participative au Brésil. In: SEMINARIO LE BRÉSIL SOUS LA LOUPE DE JEUNES CHERCHEURS, 2012, Montreal. Annales... Montreal: CERB/UQAM, 2012. 